Martinez, E., Tommelein, I.D., and Alvear, A. (2017). "Integration of Lean and Information Technology to Enable a Customization Strategy in Affordable Housing." In: LC3 2017 Volume II - Proceedings of the 25th Annual Conference of the International Group for Lean Construction (IGLC), Walsh, K., Sacks, R., Brilakis, I. (eds.), Heraklion, Greece, pp. 95-102. DOI: https://doi.org/10.24928/2017/0136

\title{
INTEGRATION OF LEAN AND INFORMATION TECHNOLOGY TO ENABLE A CUSTOMIZATION STRATEGY IN AFFORDABLE HOUSING
}

\author{
Eder Martinez ${ }^{1}$, Iris D. Tommelein ${ }^{2}$, and Ariana Alvear ${ }^{3}$
}

\begin{abstract}
Affordable housing developers in Latin America would benefit from moving away from mass housing construction and expanding the variety of choice they offer to their customers in order to create greater customer satisfaction. Admittedly, offering variety poses operational challenges that may increase cost and extend construction time, so the challenge is for developers to find the means to deliver variety without significantly affecting housing affordability. Firms outside of the construction industry have made long-term investments to integrate Lean thinking and Information Technology (IT) into production systems aiming to deliver variety with efficiency. However, such investments may be hard to replicate in the construction industry, in which investment in process innovation and technology tends to be limited. This paper presents the experience of an Ecuadorian developer who integrated Lean and IT to support a customization strategy in affordable housing delivery. The developer faced several operational challenges as a result of allowing customers to select different features of housing units. The authors describe such challenges and present the development of a novel IT tool to enable Lean construction delivery. The evaluation demonstrates that Lean with IT integration improved internal communication enabling a faster response to meet customer choices.
\end{abstract}

Keywords: Lean construction, affordable housing, information technology, housing customization, Latin America.

\section{INTRODUCTION}

Mass housing construction (MHC) is the prevailing approach to deliver affordable housing in Latin America (Rodríguez 2006). MHC allows developers to reduce construction costs and thus their sales price, thereby facilitating low-income households the purchase housing. Nevertheless, extreme standardization along with poor design and inadequate location of mass-developments result in socio-economic problems such as overcrowding and segregation (Rodríguez and Sugranyes 2005; Baena and Olaya 2013). In fact, a comprehensive study of the Inter-American Development Bank recommends developers in the Latin American region to deviate from extreme standardization and expand the choice offering in affordable housing delivery. Developers should therefore deepen their understanding of market needs and align their production processes accordingly (Bouillon 2012, p. 175). The implementation of customization strategies for affordable housing delivery may serve this purpose (Tillmann and Formoso 2008). However, as the level of

PhD, Global Process Manager, Hilti AG, Feldkircherstrasse 100, Schaan, Liechtenstein, email: edermartinezv@gmail.com

2 Professor, Civil and Envir. Engrg. Dept., Director, Project Production Systems Lab., Univ. of California, Berkeley, CA 94720-1712, USA, email: tommelein@berkeley.edu

3 MS Engineering and Project Management, Assistant Project Manager, Webcor Builders, San Francisco, CA, email: ariana.alvear@gmail.com 
choice increases, developers face operational challenges that raise costs and extend construction time (Nahmens and Bindroo 2011). Expanding the level of choice while keeping housing prices affordable implies the use of production systems able to tackle operational challenges stemming from customization without significantly increasing production costs.

In order to address the operational challenges of delivering variety, several industries have leveraged the use of IT when implementing Lean processes in their production systems. According to Kotha (1996), firms succeeding with this approach have made longterm investments in manufacturing technologies, IT, and human resources. Such longterm thinking may be hard to replicate in the housing context, especially when considering that the construction industry invests little in process innovation and technology (Egan 1998, p. 7). In fact, Andújar-Montoya et al. (2015) identify the lack of investment in IT to support processes as the main barrier for housing customization. This issue is exacerbated in Latin America since most developers in the region use outdated construction techniques and technology (CEPAL 1996; Torres and Torres 2009).

This paper describes the experience of an Ecuadorian affordable housing developer implementing Lean to support a customization strategy. Allowing customers to select some features of housing units resulted in several operational challenges. At the planning stage, the Developer experienced difficulties in responding efficiently to customer-specific requirements. To address those challenges, the Developer invested in the creation of an IT tool. This paper describes the challenges faced by the Developer and the development and implementation of an IT tool intended to address them.

\section{RESEARCH METHODOLOGY}

The authors used Action Research (AR) to conduct their study. AR is a social research methodology that combines theory generation with changing the social system through the researchers' intervention. AR has been identified as a proactive research method to address challenges in the Construction Engineering and Management field (Azhar et al. 2010) and when Lean Construction theory is the subject of study (Jang et al. 2011). The authors helped to diagnose challenges of the Developer's production system. They contributed to the creation of an IT tool, aimed to address those challenges, and then evaluated its implementation. The authors documented the development and implementation of the IT tool in order to identify the learnings of this experience.

\section{LEAN AND IT FOR HOUSING CUSTOMIZATION}

From the perspective of an affordable housing developer, it is not economically feasible to design every house according to each individual customer' preferences. Numerous preferences increase the complexity of design and make the production process complex to manage. Correspondingly, developers favor traditional manufacturing techniques to keep cost at bay, exploiting repetition and economies of scale (Ofori 2012). From a customer perspective, customization provides higher value since the housing product fulfills personal preferences (Nahmens 2007). This results in a dilemma for developers. On the one hand, they do not want to sacrifice productivity by deviating from traditional models. On the other hand, they still want to deliver increased variety to expand their market reach and potentially satisfy a broader range of customers (Nahmens and Mullens 2009). Consequently, the operational challenge is to deliver customized housing without significantly sacrificing efficiency and profit. 
In customization strategies, the degree of customer involvement typically defines the complexity of the production system. In MHC, housing design is based on market research and units are built-to-stock with practically no customer involvement during design or construction. In contrast, developers offering customization should be able to manage customer input in the production system (Barlow et al. 2003). In practice, variant customer inputs related to housing configurations (e.g., the number of rooms or colors) must be captured at the sales point and communicated in a timely fashion to production units for construction (Ozaki 2003). The amount of information increases as the level of choice expands which increases complexity. The integration of Lean processes and IT in production systems may enable developers to handle such information, thus allowing faster reaction to changing customer requirements (Riezebos and Klingenberg 2009). It may also serve as a valuable source of shared information in the supply chain, thus allowing the organization to reduce lead times (Ward and Zhou 2006). Toyota is able to produce over a million vehicle variations, including different colors, trims, and body styles (Johnson and Bröms 2000, p. 80). The company integrates IT to support Lean processes, for example by using "e-Kanbans" to enhance communication with suppliers (Kotani 2007). Lean can be complemented by IT implementation to increase the overall efficiency of the production system.

\section{PRoject CONTEXT}

The Developer is a private company, building over 10,000 affordable housing units in Duran, Ecuador. This paper focuses on the first phase of the project, corresponding to 700 housing units. Instead of building standard units, the Developer allows customers to select certain housing features. The Developer wants to allow (low-income and other) households to select the housing models which better fit their needs and budget. Nevertheless, such approach causes operational challenges. The Developer has to find the means to produce different housing configurations efficiently in order to maintain competitiveness in terms of cost and delivery time.

\subsection{Housing Configuration}

Table 1 depicts the level of customization offered to customers. Customers start their configuration selection based on nine pre-defined housing models and the number of bedrooms. Then they select the type of interior and exterior finishes, some add-ons (i.e., balconies), the phase of the project and the location of the housing unit within the block. To avoid inefficiencies in building housing units in a scattered fashion, the Developer subdivided the project site (around 180,000 $\mathrm{m}^{2}$ ) into phases linked to different delivery dates. Accordingly, selection of a location is restricted to sub-areas within the phase. The housing configuration mix results in 49 housing variations. The grey cells in Table 1 exemplify the selection of the "Hermosa" model with two bedrooms and basic finishes, located in one of the corners of block 1D. 
Integration of Lean and Information Technology to Enable a Customization Strategy in Affordable Housing

Table 1: Housing configuration

\begin{tabular}{|c|c|c|c|c|c|c|c|c|c|}
\hline Housing Model & Hermosa & Esplendida & Linda & Bonita & Divina & Bella & Grandiosa & Preciosa & Magnifica \\
\hline Number of bedrooms & 1 & 2 & & & 3 & & & 4 & \\
\hline $\begin{array}{l}\text { Interior and exterior } \\
\text { finishes }\end{array}$ & \multicolumn{3}{|c|}{ Basic } & \multicolumn{3}{|c|}{ Medium } & \multicolumn{3}{|c|}{ Premiun } \\
\hline Project stage & 1 & 2 & 3 & 4 & 5 & 6 & 7 & 8 & 9 \\
\hline Block & $1 \mathrm{~A}$ & $1 \mathrm{~B}$ & $1 \mathrm{C}$ & 1D & $2 \mathrm{~A}$ & $2 \mathrm{~B}$ & $2 \mathrm{C}$ & $3 \mathrm{~A}$ & $3 \mathrm{~B}$ \\
\hline $\begin{array}{l}\text { Location within } \\
\text { block }\end{array}$ & \multicolumn{4}{|c|}{ Intermedium } & \multicolumn{5}{|c|}{ Corner } \\
\hline
\end{tabular}

\subsection{Practical Challenges}

The Developer faced several challenges capturing and communicating housing configuration data (Table 1) to the construction team, and developed a process (Figure 1)to do manage them. The sales team consolidates housing configurations and communicates them to the planning team using an Excel report. The planning and construction teams analyze the data and define the most appropriate construction workflow given the housing configuration mix. The teams use a printed version of the latest site plan to map out the different housing configurations in order to have a visual representation of the workflow and to define the schedule accordingly. This information is then used in the field for construction.

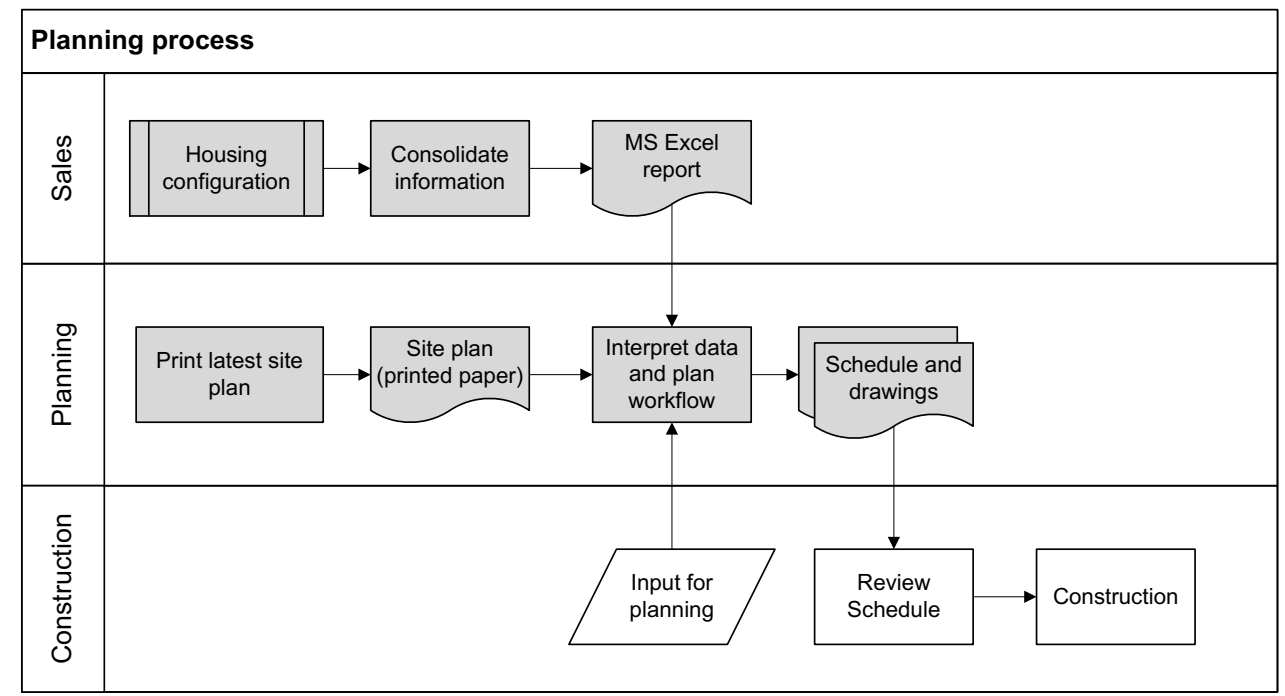

Figure 1: Planning process

The process seems to be straightforward but it has several flaws. First, the fast-paced construction method used in the project allows for construction of 2 houses per day. Given the variety in housing configurations, it is very difficult to process daily changes required in the field without incurring any mistakes. Second, every time customers change their selection (e.g., order cancellation, or change in the model, type of finishes, or location), the planning and construction teams have to re-do the process to adjust the construction schedule. Third, the planning and construction teams do not have real-time access to housing configurations. In practice, they work with outdated information until the sales department releases an updated Excel report. Unquestionably, the planning process was complicated and time-consuming. Manual data processing of new orders and adjustment of existing ones took up to two days. The response time of the production system was 
extended due to the manual effort required to process and communicate housing configurations. Consequently, the Developer wanted to automate the steps shown in grey in the process (Figure 1) by implementing an IT tool called Interactive Plan (IP). The envisioned IP would help sales agents capture customer orders and plot them in a project plan allowing the construction team to access sales data in real time.

\section{INTERACTIVE PLAN (IP)}

\subsection{IP Architecture}

The IP system is built on IDempiere, an open source Enterprise Resource Planning (ERP) platform. IDempiere is based on JAVA and can be operated in a physical or virtual infrastructure making it accessible through the internet with no need of local software installation (BMLaurus 2015). In IP, housing configuration data is captured at the sales point and sent to the IDempiere database. The data is then translated into color/shape codes and plotted in a site plan which creates an interactive plan accessible in real time. Housing configuration data in the IDempiere database is mapped out on the site plan by overlapping two layers of information through JAVA code. Figure 2 outlines the system code. Layer 1 corresponds to a high definition picture of the site plan, where every lot location is assigned unique $(\mathrm{X}, \mathrm{Y})$ coordinates.

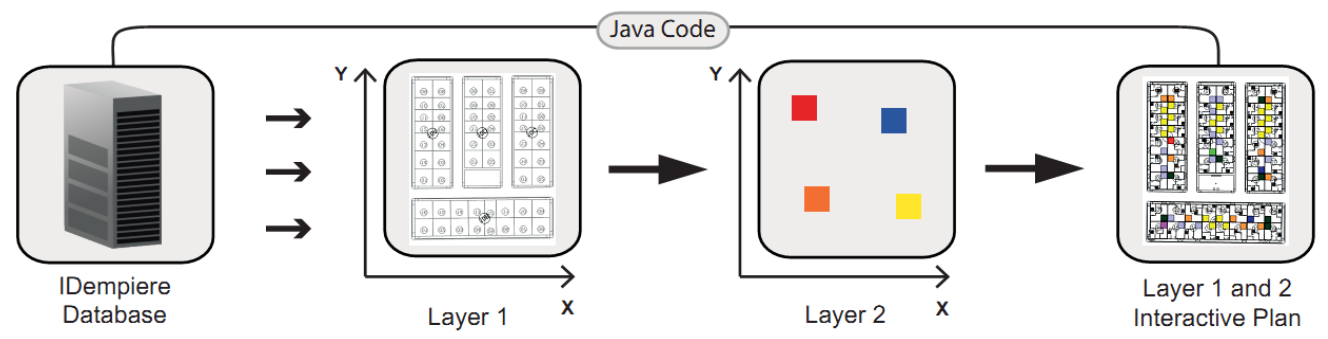

Figure 2: Schematic representation of JAVA code for Interactive Plan

Layer 2 is programmed to translate housing configurations into color/shape codes using the same $(\mathrm{X}, \mathrm{Y})$ locations defined in layer 1 . In simple terms, layer 2 acts as a transparent slide containing color/shape codes according to housing models selected by customers. Since both layers have the same (X, Y) coordinates, the overlap of the two layers of information generates IP in the IDempiere environment showing the housing configurations anchored to locations in a visual way.

\subsection{User Interface}

IP can be consulted in real time over the internet. Every time the company receives a customer order, that order is promptly captured and depicted in the system. IP also captures changes in customer orders. Figure 3 shows the user interface. The right side depicts customer selections anchored to the housing unit's corresponding location on the site plan. The left side shows the color/shapes legend that allows users to filter the information. For instance, a user may want to analyze information for a specific delivery date or to verify the locations of specific housing configurations. In addition, IP can be zoomed in or out to a specific project area users want to see on the screen. Moreover, users can access further information (e.g., order date, customer name, transaction cost) by clicking the color/shape codes. 


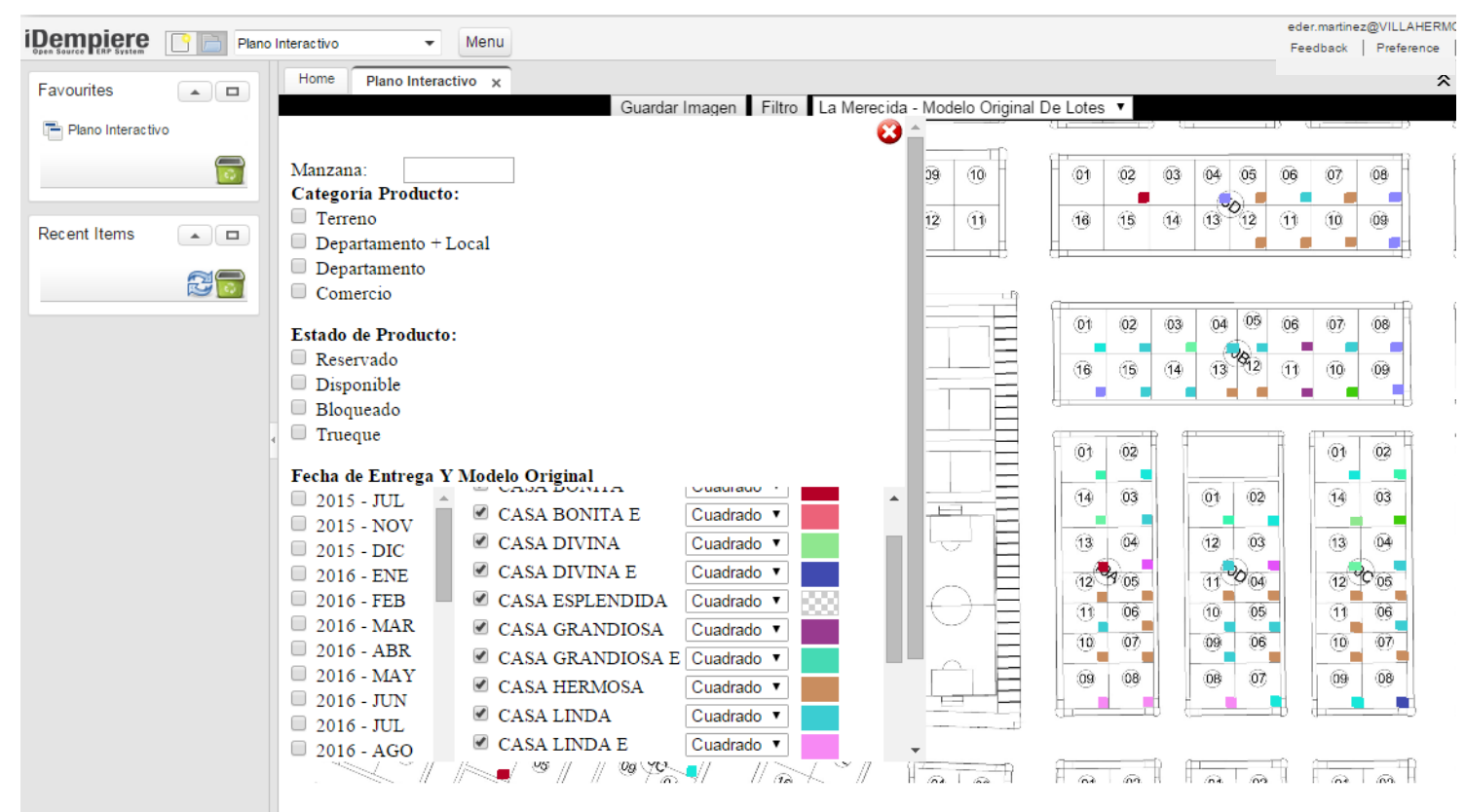

Figure 3: Interactive Plan user interface

\subsection{Results}

Reduced lead time. IP allowed the developer to automate several steps in the process of capturing and communicating housing configuration data (grey steps in Figure 1). This automation improves the process by allowing the planning and construction teams to have instant access to the necessary information to start construction.

Improved communication. IP processes and depicts housing configuration data in a visual and interactive way which facilitates internal communication.

Shared information. IP offers shared information. In addition to housing configuration locations, IP contains other type of data (e.g., transaction dates and customer information) that serves other departments in the organization.

\subsection{IP Limitations and Further Development}

The feedback provided by users helped identify limitations of IP as well as aspects where it can be improved and further developed. First, the current version of the IP only allows exporting of information in a JPG file. The JPG file has several limitations in terms of compatibility with other software commonly used in the construction industry. This situation limits the use of IP for other purposes. For example, exporting IP in a DWG file could help the design team update the project design according to final housing configurations (e.g., as-built drawings). Second, the software is not able to receive inputs directly in the IP interface (Figure 3). IP allows data input only in IDempiere, limiting its use for other purposes. For example, the construction team may want to input information about construction progress to use in project control.

\section{CONCLUSIONS}

This paper presented the creation and implementation of Interactive Plan (IP), a novel IT tool that supports Lean process delivery of variety in affordable housing in on a project in Latin America. 
The implementation of IP improved the process of capturing and communicating housing configuration data in several ways. First, manual efforts are minimized by the automation of the transition reports from the sales team to the planning and construction teams. This automation reduces lead time and the likelihood of mistakes from processing information. Second, IP processes housing configuration data and depicts it in a visual way, which eases internal cross-department communication within the organization. Third, IP offers shared information not only for construction, but also for administrative purposes such as purchase dates, transactions, and cost. In alignment with Lean thinking, IP also serves as a tool for continuous improvement. The IP database allows the Developer to learn about customer preferences and improve their customization strategy for the following stages of the project. For instance, the Developer may consider discontinuing housing configurations ranked at the bottom of sales. Similarly, the IP database may provide the Developer with valuable information about the housing features that customers prefer. In future stages, the Developer can focus on such aspects in order to provide the customer with enhanced value in affordable housing provision.

\section{REFERENCES}

Andújar-Montoya, M. D., Gilart-Iglesias, V., Montoyo, A., and Marcos-Jorquera, D. (2015). "A construction management framework for mass customisation in traditional construction." Sustainability, 7(5), 5182-5210.

Azhar, S., Ahmad, I., and Sein, M. (2010). "Action Research as a proactive research method for construction engineering and management." J.Constr.Eng.Manage., 136(1), 87-98.

Baena, A., and Olaya, C. (2013). "Vivienda de interés social de calidad en Colombia: hacia una solución integral [High-quality affordable housing in Colombia: towards an integral solution]." Sistemas \& Telemática, 11(24), 9-26.

Barlow, J., Childerhouse, P., Gann, D., Hong-Minh, S., Naim, M., and Ozaki, R. (2003). "Choice and delivery in housebuilding: lessons from Japan for UK housebuilders." Build.Res.Inf., 31(2), 134-145.

BMLaurus (2015). "Software ERP - IDempiere." < http://www.bmlaurus.com/\#!lidempiere/c1qvr> (Jun. 19, 2015).

Bouillon, C. P. (2012). Room for development: housing markets in Latin America and the Caribbean. Palgrave Macmillan, New York, NY, USA.

CEPAL. (1996). "La produccion de la vivienda en America Latina y el Caribe [Housing production in Latin America and the Caribbean]." CEPAL, Santiago, Chile.

Egan, J. (1998). "Rehtinking construction: The report of the construction task force." Department of Trade and Industry, UK, London, UK.

Jang, W., Choi, S., Han, S. H., Im, K., and Jung, D. (2011). "Integrated framework for productivity improvement: action research approach with Lean Construction theory." P. of the 28th Int'l. Symp.on Autom. and Robotics in Const. ISARC, IAARC, Seoul, Korea, 1134-1140.

Johnson, H. T., and Bröms, A. (2000). Profit beyond measure: extraordinary results through attention to work and people. Free Press, New York, NY, USA.

Kotani, S. (2007). "Optimal method for changing the number of kanbans in the e-Kanban system and its applications." Int'l. J. of Prod.Res., 45(24), 5789-5809.

Kotha, S. (1996). "From mass production to mass customization: the case of the national industrial bicycle." European Management Journal, (5), 442-450. 
Nahmens, I. (2007). "Mass customization strategies and their relationship to lean production in the homebuilding industry." Ph.D. Diss. Univ. of Central Florida, Orlando, FL, USA.

Nahmens, I., and Bindroo, V. (2011). "Is customization fruitful in industrialized homebuilding industry?" J.Constr.Eng.Manage., 137(12), 1027-1035.

Nahmens, I., and Mullens, M. (2009). "The impact of product choice on Lean homebuilding." Construction Innovation, 9(1), 84-100.

Ofori, G. (2012). Contemporary issues in construction in developing countries. Spon Press, New York, NY, USA.

Ozaki, R. (2003). "Customer-focused approaches to innovation in housebuilding." Constr.Manage.Econ., 21(6), 557-564.

Riezebos, J., and Klingenberg, W. (2009). "Advancing lean manufacturing, the role of IT." Comput.Ind., 60(4), 235-236.

Rodríguez, A., and Sugranyes, A. (2005). Los con techo: un desafío para la política de vivienda social [People with a roof: a challenge for the affordable housing policy]. Ediciones Sur, Santiago, Chile,.

Rodríguez, I. (2006). "Vivienda social latinoamericana: la clonación del paisaje de la exclusión [Latin American affordable housing: cloning a landscape of exclusion]." ACE: Arquitectura, Ciudad Y Entorno, 1(2), 20-55.

Tillmann, P. A., and Formoso, C. T. (2008). "Opportunities to adopt mass customization: a case study in the Brazilian house building sector." P. of the 16th Annual Conference of the International Group for Lean Construction (IGLC), IGLC, Manchester, UK, 447458.

Torres, J., and Torres, E. A. (2009). "El contexto económico, social y tecnológico de la producción de vivienda social en América Latina [Economic, social, and technological context for affordable housing production in Latin America]." Enc. Latinoam. de Gestión y Econo. de la Const. (ELAGEC), Bogotá, Colombia.

Ward, P., and Zhou, H. (2006). "Impact of Information Technology integration and Lean/Just-In-time practices on lead-time performance." Decision Sciences, 37(2), 177203. 